\title{
SOBRE DOR, SOFRIMENTO E ESPERANÇA: O NOVO CORONAVÍRUS E A CONDIÇÃO HUMANA NO ANTROPOCENO ${ }^{1}$
}

\author{
ABOUT PAIN, SUFFERING AND HOPE: THE NEW CORONAVIRUS AND THE \\ HUMAN CONDITION IN THE ANTROPOCENE
}

\author{
Flávio Bezerra BARROS
}

"Laudato si', mi' Signore - Louvado sejas, meu Senhor, cantava São Francisco de Assis. Neste gracioso cântico, recordava-nos que a nossa casa comum se pode comparar ora a uma irmã, com quem partilhamos a existência, ora a uma boa mãe, que nos acolhe nos seus braços: "Louvado sejas, meu Senhor, pela nossa irmã, a mãe Terra, que nos sustenta e governa e produz variados frutos com flores coloridas e verduras". (Cantico delle creature: Fonti Francescane, 263).

\section{Palavras iniciais...}

Em 18 de março de 2020 a imprensa lusa noticiou por seus meios de comunicação impressos e televisivos o falecimento do presidente do Grupo Espanhol Santander em Portugal. Vítima da covid19, o senhor António Vieira Monteiro, 73 anos, perdeu a disputa contra o inimigo invisível. Sua filha, após viver o drama de não poder velar o corpo do seu progenitor e fazer a despedida ao modo ocidental, refletiu, dizendo: "Меи pai viveu mergulhado no mundo do dinheiro, era um homem rico e morreu precisando de algo que é gratuito: o ar", fazendo referência à incessante e desesperadora busca por oxigênio, condição daqueles acometidos com a patologia que mata sufocando, sem dó nem piedade. Penso que não adianta, nesta altura, falar de estatísticas, números, pois tudo nos soa como informação caduca diante da galopante investida do parasita feroz que se alimenta da carne humana, e somente humana. Aliás, fala-se, alhures, que as autoridades sanitárias ao redor do mundo já não dão conta de registrar, com a celeridade que a matéria requer, os casos positivos e óbitos; então, as notificações anunciadas podem não refletir (apostaria nisso) a realidade. Ontem mesmo (dia 1 de abril de 2020), em conversa por WhatsApp com uma amiga equatoriana, estava ela a me relatar a situação aterrorizante pela qual passa seu país diante da pandemia, sob o regime do boçal e neoliberalista Lenin Moreno. Vê-se pelas calles da segunda maior cidade do Equador, Guayaquil, pessoas morrerem à míngua, sem qualquer tipo de assistência frente ao sufocamento do quase inexistente sistema de saúde, demonstrando, assim, os efeitos funestos da política ali implantada. O cenário de dor e sofrimento, do povo equatoriano, está escancarado para quem quiser ver. O Diário Causa Operária, jornal editado no Brasil, em sua edição de quinta-feira, 2 de abril de 2020 - Edição $\mathrm{N}^{\circ}$ 5.966, trouxe a cruel notícia: Política neoliberal de Moreno transforma Equador em cemitério gigante - A política do traidor Lenin Moreno está conduzindo o povo equatoriano à morte, com corpos sendo jogados nas ruas das cidades. Não quero estender este prelúdio com mais exemplos dolorosos, porque as páginas não bastariam, pois todos somos sujeitos cognoscentes dessas vicissitudes, elas próprias tão ligeiras.

Os dias de confinamento, longe da correria cotidiana da cidade grande e adoecida, têm servido para ampliar a capacidade de concentração. Tenho procurado, de modo hercúleo, ouvir os recados dos outros seres sencientes e, ao mesmo tempo, me permitido certa reflexão. A despeito dessa

1Agradeço, de maneira muito especial, ao Prof. Emmanuel Duarte Almada, da Universidade do Estado de Minas Gerais (UEMG). e à Prof a Glória Regina Gomes Amaral, da Universidade Federal do Pará (UFPA), pelas leituras críticas ao texto. 
perspectiva, talvez um ponto de vista, digo sobre a escuta aos outros "viventes" que conosco compartilham este imenso mundo, escutei, em janeiro passado, em entrevista dirigida a um mestre de carimbó, na Ilha do Marajó, que precisávamos entender o que as matas, os rios e as estrelas têm a nos falar. Com efeito, pensar sobre as alteridades é um valoroso exercício sobre estar aqui, compartilhando esta casa comum, a Pachamama, onde todos e todas somos feitos do mesmo barro e da mesma lama, como bem profetiza Nanã, e que tudo, absolutamente tudo, no final das contas, nos é concedido a título de empréstimo. Esta filosofia não é coisa vã. E há tantos a viver mergulhados na senda das ilusões, achando que ouro e prata podem comprar o ar. Mera falácia em tempos de coronavírus. A rapariga portuguesa do início desse texto que o diga. Urge nos reconectarmos com a natureza, da qual jamais deveríamos ter nos afastado!

Neste ensaio descrevo reflexões acerca dessa severa crise pela qual o mundo vem atravessando, partindo da minha visão de pesquisador e pessoa que trabalha com gentes das matas $\boldsymbol{e}$ rios da Amazônia. Um mundo que subitamente se tornou mais global e indiviso perante uma realidade comum: o coronavírus (ele não reconhece as fronteiras inventadas pelos humanos nesta casa comum!). Ando me perguntando: Quais aprendizados podemos tirar dessa preciosa experiência da efemeridade humana? Por que estamos, nós humanos, vivendo essa carnificina? O que fizemos com a nossa ciência, tecnologia, inteligência e, pasmem, essa tão prestigiosa e arrogante racionalidade do sapiens, que nada, nem ninguém, consegue frear, pelo menos por agora, essa unidade biológica que vai deixando nas certidões de óbito o carimbo da causa mortis: covid-19? Seria uma reação da Terra, tão combalida, às agressões protagonizadas pelas mentes e mãos humanas, cuja "sabedoria" transformou a natureza em mercadoria? Pensemos. O tempo vivido não se trata de uma estória de avatar como aquelas das histórias em quadrinhos ou do cinema. Ela é real e acontece agora, no Antropoceno.

\section{Sobre comer bichos e a possível origem do SARS-CoV-2}

Há sete coronavírus humanos (HCoVs) conhecidos, entre eles o SARS-COV (que causa síndrome respiratória aguda grave), o MERS-COV (síndrome respiratória do Oriente Médio) e o SARS-CoV-2 (vírus que causa a doença COVID-19) (OPAS, 2020). É sabido que o centro de origem da doença se deu em Wuhan, capital e maior cidade da província de Hubei, na China. Há dissenso sobre como esse novo coronavírus se originou. Mas existe uma narrativa que pulula no discurso de cientistas, imprensa e toda a sorte de gente, assentada na dimensão da cultura alimentar dos chineses. Comenta-se que uma parte significativa (cerca de 27 pessoas) dos primeiros 41 infectados pelo coronavírus, que apresentavam tosse seca e febre alta antes de desenvolver pneumonia, havia frequentado um mercado de comida onde o comércio de animais silvestres vivos é uma prática corrente. Logo a seguir ao surto do vírus, o aludido mercado fora fechado. $O$ povo chinês, assim como todas as sociedades humanas, tem hábitos alimentares particulares. E comer animais silvestres faz parte dos costumes desses asiáticos. Os morcegos (Chiroptera) e pangolins (Pholidota) são exemplos desses animais silvestres que compõem a dieta das pessoas. Vários desses animais são hospedeiros intermediários ou definitivos de vírus, os quais não causam doença ou morte nestes animais.

Li e ouvi relatos em meios digitais de que tais animais são vendidos em condições precárias de acondicionamento e higiene. Se o novo coronavírus veio de fato de alguma dessas espécies, não há certeza. Contudo, é razoável esclarecer que vários grupos humanos pelo mundo comem animais silvestres, inclusive os brasileiros. Neste sentido, não seria sensato condenar uma cultura inteira a partir de seu costume alimentar. Faz-se necessário, sim, compreender as circunstâncias que rodeiam a situação antes de emitir qualquer parecer. Incontáveis vídeos, enviados pelas redes sociais, anunciavam o juízo final aos chineses porque comiam animais horrendos de todo tipo e espécie, ou declarando sua responsabilidade pela tragédia humanitária. Em tom profético, condenavam: Foram eles que espalharam essa praga pelo mundo.

A relação diplomática entre o Brasil e a China ficou estremecida por alguns dias. Atribuiu-se o "clima pesado" aos gestos irresponsáveis e pouco contidos do deputado federal Eduardo Bolsonaro ao postar em suas redes sociais agravos ao povo chinês. Como dizia Geertz, em matéria de cultura, a palavra mais traiçoeira é a lógica. Portanto, não julguemos. Embora não caibam comparações, pois cada caso é um caso, os povos indígenas, os não indígenas e povos tradicionais têm por cá o hábito de comer macaco assado ou guisado no leite da castanha-do-pará (Bertholletia excelsa), ou cobra sucuri (Eunectes sp.) moqueada. Paca (Cuniculus paca), tatu (Dasypodidae), cutia (Dasyprocta leporina), mocó (Kerodon rupestres), capivara (Hydrochoerus hydrochaeris), todo esse arsenal de caças integra a dieta de inúmeros grupos sociais Brasil afora. No Pará, nalgumas cidades do interior, come-se 
mucura (gambá, Didelphis spp.), que dizem ter gosto de galinha. Na Ilha do Marajó, e noutras partes do Pará, não é difícil encontrar apanhadores e comedores de turu (Teredo sp.), uma espécie de molusco com aspecto de verme. As pessoas os apanham em paus apodrecidos que ficam cheios desses bichos, fonte rica de proteína e afrodisíaco. Dentro do próprio país há quem adore comer caças, assim como há quem abomine tal intento. Os escritos de viajantes naturalistas, desde a época dos descobrimentos, relatam práticas zoofágicas e como estas se disseminaram desde os primeiros contatos entre os ameríndios e europeus. A esse despeito, Nunes Pereira (1974, p. 213), escreveu:

Manoel de Sousa Lobo, com os seus companheiros, viajando pelo Rio Aripuanã, assim como conservavam ovos de tracajá, com idêntica preocupação, também conservavam crâneos de macacos, cujos miolos eram devorados, pingando-se neles gotas de limão, pitadinhas de sal e molho de pimenta malagueta. Aquilo era, para o paladar do grande amigo e dos seus companheiros de explorações de castanhais e seringais, uma verdadeira delicatesse, dessas que só os gourmets parisienses e berlinenses apreciam.

Como se vê, em tempos de covid-19, a tese de que apenas os chineses comem coisas esquisitas e perigosas, não encontra sustentação. Afinal, o que é mesmo comida esquisita? Esquisita para quem? Lembro novamente o pensamento geertiziano: em termos de cultura, a palavra lógica é a mais traiçoeira. Importante seria, neste tempo de coronavírus, haver esforço interdisciplinar e dialógico para compreender as diferentes faces que permeiam a questão.

\section{Capital, fronteira, políticas neoliberais e os ensinamentos da pandemia}

Uma coisa é certa: a pandemia veio para todos. Noções como fronteira, raça, cultura, gênero, idioma, condição social, território, religião, cosmovisão, são para o vírus estranhas e estrangeiras. Ele é democrático e global, pois não faz distinção entre os seres humanos, muito embora as estatísticas apontem para as pessoas de faixa etária mais elevada e portadoras de enfermidades pré-existentes como sendo o conjunto da população mais afetado. A história vivida no tempo presente pode nos ensinar várias lições. Uma delas pode ser a ideia de fronteira, essa invenção (des)humana que serviu para separar as nações, dividindo-as entre ricas e pobres, colonizadas e colonizadoras. As ricas acessam bens como saúde e educação de qualidade, alimento em quantidade (nem sempre em qualidade), enquanto as demais enfrentam toda a sorte de violência, guerra civil, fome e falta de moradia digna, saúde e educação em níveis razoáveis. Conflitos sociais, diásporas e migrações em massa ocorrem quando aqueles que, como humanos que são, desvalidos, querem ter o mesmo direito de viver como os ricos. Quantos corpos sucumbiram no Mar Mediterrâneo em meio a investidas frustradas de refugiados para ingressar no continente abastado, em busca do "paraíso"? Agora o coronavírus vem nos ensinar: fronteira é uma ilusão!

Nesta casa comum, todos são iguais na diversidade e compartilham a mesma condição de fragilidade. Aprendamos. Movidos pelo capital mais do que pela vida, chefes de Estado em todo o globo vivem o desassossego de ver a economia corroendo, fábricas fechadas, linhas de produção estagnadas, desempregos a aumentar. O céu está desabando! Num piscar de olhos, as desigualdades ficaram nuas, sob o efeito de um espelho chamado covid-19. A pandemia nos ensina outra lição: o que é riqueza, afinal, se agora ela não está servindo para salvar vidas humanas? Ouro e prata não se transformam em ar, assim como não se metamorfoseiam em comida ou bebida. Mas as políticas neoliberais estão aí, gerando distorções sociais, retirando do Estado o papel de proteção ao cidadão, na medida em que favorecem as grandes corporações, as instituições bancárias e a elite, causando dor e sofrimento ao povo trabalhador, privatizando instituições, arquitetando reformas devastadoras.

Na América Latina, a Argentina, o Chile, a Colômbia e, sobretudo, o Brasil, passaram ou estão a enfrentar regimes perversos. O algoz ágil e imperceptível batizado de novo coronavírus manda mais um recado: podiam estar mais preparados para o combate se estivessem com mais imunidade, e se todo o contingente da sociedade mundial comesse melhor (sem veneno), se houvesse mais dinheiro para a ciência, educação e saúde, e se o "consumo" tivesse outra lógica, a do bem viver e não a do lucro. É justamente a segunda, a do lucro, que potencializa doenças como depressão, diabetes, câncer, dentre outras. Para um treino epistêmico, tomo como empréstimo o dizer do xamã yanomami Davi Kopenawa: "Os Brancos não sonham tão longe como nós. Dormem muito, mas só sonham consigo mesmos". Há muita profundidade neste pensamento indígena. 


\section{Nem tudo está perdido: saber ouvir e aprender com os outros}

São raras, por esses tempos de pandemia, as notícias escatológicas sobre o clima, derretimento das geleiras, branqueamento de corais, enchentes, tsunamis, furacões, incêndios. Instituições comunicam que peixes estão ressurgindo em rios altamente poluídos e há menos poluição no ar, no solo e nos sistemas hidrológicos. A natureza está em êxtase e dá sinais de regeneração. Poderíamos dizer que esta seria uma benesse da pandemia? Reflitamos. Certo é que a humanidade precisa urgentemente revisar conceitos e fazer o exame do status quo. O sistema de funcionamento da humanidade dá sinais de fracasso. No dia 4 de abril deste ano de 2020, Donald Trump, presidente dos Estados Unidos, disse para todo mundo ouvir: "Os EUA precisam de todas as máscaras, não as peguem", declaração feita por ele em razão do suposto confisco dos equipamentos de proteção individual e outros aparatos que teriam sido comprados da China pelo Brasil, Alemanha e França. Não se pode considerar tamanho egoísmo uma banalidade em época de aperreio. Isso é atrocidade. Por outro lado, as comunidades tradicionais indígenas e não indígenas e muitos grupos de camponeses nos ensinam sobre como viver bem na casa comum.

A questão de fundo para estes grupos sociais é a relação com a natureza. E o termo relação deve aqui ser compreendido no seu sentido mesmo de enlace, vínculo, dependência. $O$ vínculo, neste diapasão, não se descortina sob o efeito da dominação, mas de práticas cosmológicas que produzem sistemas integrados. Como desvela o cântico de São Francisco, no princípio desse ensaio, ela, a casa comum, nos acolhe em seus braços e é com ela que partilhamos a existência. Como somos capazes de fazer tanto mal a quem nos presenteia, de forma dadivosa, com flores coloridas e verduras? São estes outros seres humanos que continuam ouvindo da natureza o que ela quer de nós. O que chamamos de natureza, termo que herdamos de nossa história colonial, para povos originários tem outro significado ou explicação; nem sequer tem este nome (hutukara, para os yanomami, pachamama, para os quéchua...). Como disse Boff (2020), em artigo recentemente publicado: O planeta não só possui vida sobre ele. Ele próprio é vivo. Emerge como um Ente vivo, como um sistema que regula os elementos físico-químicos e ecológicos. Chamaram-no de Gaia.

A vida desses povos é marcada por outras lógicas que reúnem a memória dos seus ancestrais, a observação dos ciclos da natureza (é preciso saber se comunicar com os ventos, a lua, as estrelas, as matas, os rios, os animais, as plantas, o sol e a chuva...), a alegria de compartilhar os presentes de hutukara em forma de alimento, abrigo, vestes, cura. $\mathrm{O}$ cuidado com os demais seres e entidades que povoam esta casa comum, uma vez que estes seres e estas entidades possuem alma, igualmente se constitui como ordem da vida em comunhão com o cosmo. É por esta razão que a dádiva é essencial entre os povos e comunidades tradicionais, pois o sentido da coletividade, da solidariedade e do cuidar do outro (e esse outro guarda uma infinidade semântica enorme), é regra que deve ser observada desde sempre.

Os sistemas alimentares dessas comunidades são repletos de processos que envolvem múltiplas sabedorias, histórias dos cultivares, manejo da agrobiodiversidade, trabalho familiar e comunitário, diversidade de espécies, sociabilidades que vão desde o preparo da terra para plantar até a transformação dos produtos colhidos em comida. A observação dos solos, dos sistemas hídricos e toda dinâmica da floresta são levados em conta nas tomadas de decisão, conjunto de práticas que torna esses alimentos livres de injustiça social e agravo à natureza. Tais alimentos encontram-se envoltos a celebrações, culto a divindades, aproximam vizinhos para a troca de variedades, fortalecendo laços familiares e de amizade, e promovendo o que biólogos e agrônomos chamam de conservação genética da biodiversidade in situ; ou seja, esses alimentos nutrem o corpo e revigoram a alma. O que está em jogo para estes grupos, afinal, é o bem viver e não o lucro. Davi Kopenawa (2015), neste sentido, em $A$ queda do céu, definiu "nossa sociedade não indígena" como o "povo da mercadoria".

As "sociedades nacionais" e os governos ao redor do mundo, pouco ou nada (re)conhecem sobre os modos de vida desses povos e sua relação com a pachamama. Aliás, povos indígenas e comunidades tradicionais geralmente são rotulados como atrasados, primitivos e um empecilho ao desenvolvimento. Mas são em seus territórios que repousam as maiores reservas minerais do planeta, as florestas mais ricas em biodiversidade ainda por conhecer e os estoques de água doce límpida. Por quê? Quem são os atrasados, afinal? E os governos, aliados às grandes multinacionais e homens de poder, agem como abutres para explorar tamanhas riquezas que, para os povos originários, não são mercadorias. As Instituições do Estado e outras a ele não vinculadas não sabem informar os incontáveis casos de assassinatos e violências a lideranças indígenas, quilombolas e camponesas que, em nome da defesa do meio ambiente e de seus direitos territoriais, perderam suas vidas. 
O Brasil é um excelente exemplo do que se está a narrar, pois, sendo o país detentor de cerca de $20 \%$ da biodiversidade do mundo, os povos tradicionais e povos indígenas enfrentam seu pior pesadelo, sob o regime de extrema direita do presidente Bolsonaro. Em tempos de covid-19, ficando ainda no contexto brasileiro, pouca ou nenhuma ação existe para conter o avanço desse infortúnio sobre os territórios indígenas, quilombolas e de tantos outros grupos sociais. Apesar de viverem em conexão com a pachamama, permanecem "invisíveis" (visíveis são o ouro, a bauxita e a madeira de seus territórios) aos olhos do governo federal, cujo presidente está mais preocupado com a proteção da economia do que com a salvaguarda das vidas humanas. Aqueles governos que escolheram pela primeira opção, não levando em consideração o embasamento da ciência e autoridades especializadas quanto ao isolamento social, estão agora chorando o leite derramado ao ver tantas vidas ceifadas.

\section{A virada do jogo: é possível uma nova ordem?}

$\mathrm{O}$ vírus causou um rebuliço na vida dos seres humanos. Como sujeitos sociais que somos, estamos experimentando novos comportamentos, os quais são verdadeiros sacrifícios para muitos. Sair à rua, frequentar bares, fazer e receber visitas, conversar de pertinho, dar aquele abraço apertado, trocar beijinhos, curtir aquele bate-papo na feira, de repente tornaram-se atitudes quase ilícitas, tamanho é o medo de um possível contágio. Dentro de suas casas, para quem as têm, as pessoas estão acionando como nunca sua capacidade imaginativa com vistas a ressignificar o jeito de viver sob a recomendação do confinamento. É uma prova de vida ou morte. O tempo, aquele para curtir a família e os amigos, assistir a um filme, cuidar das plantas ou dos livros, fazer aquela faxina antiga, arrumar o guarda-roupa, telefonar para um colega distante, de repente bate à porta. Porém, com ele podemos fazer determinadas coisas, outras, não. Vale à pena pagar o preço desse tempo disponível, imposto a nós nessas circunstâncias? Ele tem servido de teste para avaliarmos a qualidade das relações humanas com os de perto e perscrutar nossa natureza humana diante daqueles cujo enfrentamento à pandemia segue em condições precárias e desumanas. Com a mesma celeridade com que grupos estão organizando redes de solidariedade para auxiliar os contingentes de desfavorecidos, fornecendo comida, álcool em gel, materiais de higiene, máscaras de proteção, elaborando materiais didáticos para comunidades indígenas em suas línguas maternas, outros, porém, veem no sofrimento alheio a oportunidade de obter algum tipo de lucro, demonstrando sua incapacidade de aprender com a tragédia alheia. Prefiro acreditar na força dos primeiros e na renovação humanística dos segundos.

Acontece, em todo o mundo, um movimento incrível de solidariedade e compaixão, atributos humanos que independem de religião, idioma, orientação sexual ou classe social. Apesar da dor e do sofrimento vividos por famílias que perderam seus entes queridos, as maneiras de resistir ao vírus potente estão em trânsito. Haverá muita tarefa para o pós-pandemia. Quais alternativas ou caminhos se anunciam? As respostas são inúmeras e algumas pistas estão por entre as singelas linhas dessa escritura. Não custa acreditar que uma nova ordem possa surgir. Utopia? Não sei. Mas são as utopias que impulsionam transformações.

Caminhando para o final desse texto, gostaria de prestar homenagem aos profissionais de saúde, deliberadamente médicos e médicas, enfermeiras e enfermeiros, técnicos e técnicas de saúde, psicólogos e psicólogas, e todo conjunto dessa parte da sociedade que tem se dedicado com maestria e perseverança à missão de salvar vidas, mesmo arriscando as suas. Aos trabalhadores e trabalhadoras do mar e dos rios que nos trazem o peixe, essa dádiva das águas oferecida pela pachamama, mas que, sem as mãos e sabedoria do ser humano, de nada valeria para ele. Aos agricultores e agricultoras familiares (numa dimensão amplificada do termo), que cultivam na terra verduras, frutas, grãos e raízes que nos dão a força e a energia vitais para seguirmos a jornada com esperança de renovação e calmaria para esse tempo vertiginoso. A todos e todas cientistas que se encontram debruçados e debruçadas, no momento que escrevo estas linhas, com o propósito de encontrar a cura do vírus, rendemos viva! Aos homens e mulheres viventes em todos os confins dessa casa comum que, d'algum jeito estendem sua mão aos irmãos e irmãs, oferecendo palavras doces, enviando cartinhas com mensagens de paz e encorajamento, fazendo uma prece, dirigindo um olhar ou promovendo um concerto pela janela, ou ainda, visitando o ancião em resposta às suas necessidades materiais e emocionais, todos os louros! Aos profissionais de todas as áreas essenciais, cujo trabalho não cessou mesmo diante do confinamento. Aos santos e santas, pajés, sacerdotes e sacerdotisas, xamãs, de todos os credos, que estão a interceder pela humanidade. Aos colegas, Universidades, Institutos de Pesquisa, ONGs e demais organizações e instituições que estendem suas mãos aos povos da floresta, povos e 
comunidades tradicionais, povos indígenas, oferecendo amparo, conselhos, cartilhas em suas línguas maternas sobre a covid-19, uma homenagem singela. A hutukara, OBRIGADO!

\section{Um gesto de ternura para cultivar esperança...}

Para encerrar, compartilho uma das tarefas que mais gostaria de desenvolver e o tempo "não deixava": plantar. Em janeiro de 2020, ao ministrar aulas no Campus de Soure da UFPA, vi imensos flamboyants (Delonix regia Raf.) floridos, belos e viçosos espalhados por diversas ruas desta cidade amazônica-marajoara. Por onde passava e notava as árvores, as fotografava e logo apanhava suas sementes esparramadas pelo chão. Trouxe-as para minha casa em Belém, prometendo a mim mesmo um dia plantá-las, mesmo sabendo da dificuldade de sua germinação. Confinado, encontrei tempo para esse fim. Busquei na internet uma técnica para quebrar a dormência das sementes, em seguida as plantei em pequenos recipientes. Para minha surpresa, foi um sucesso. As sementes germinaram.

Originária da Ilha de Madagáscar, no continente africano, esta árvore de flores rubras intensas encanta a toda a gente. Anseio que estes "filhos e filhas" de flamboyants, que se desenvolveram absorvendo as energias da terra, do sol, da água e do cosmo, possam se apresentar aos nossos olhos, almas e mentes, como inspiração para sonharmos com um mundo diferente agora e após concluirmos essa difícil travessia. Que este pedacinho da imensa beleza do mundo, em modo de flores, traga magia e encantamento para nossas vidas. Ofereço!
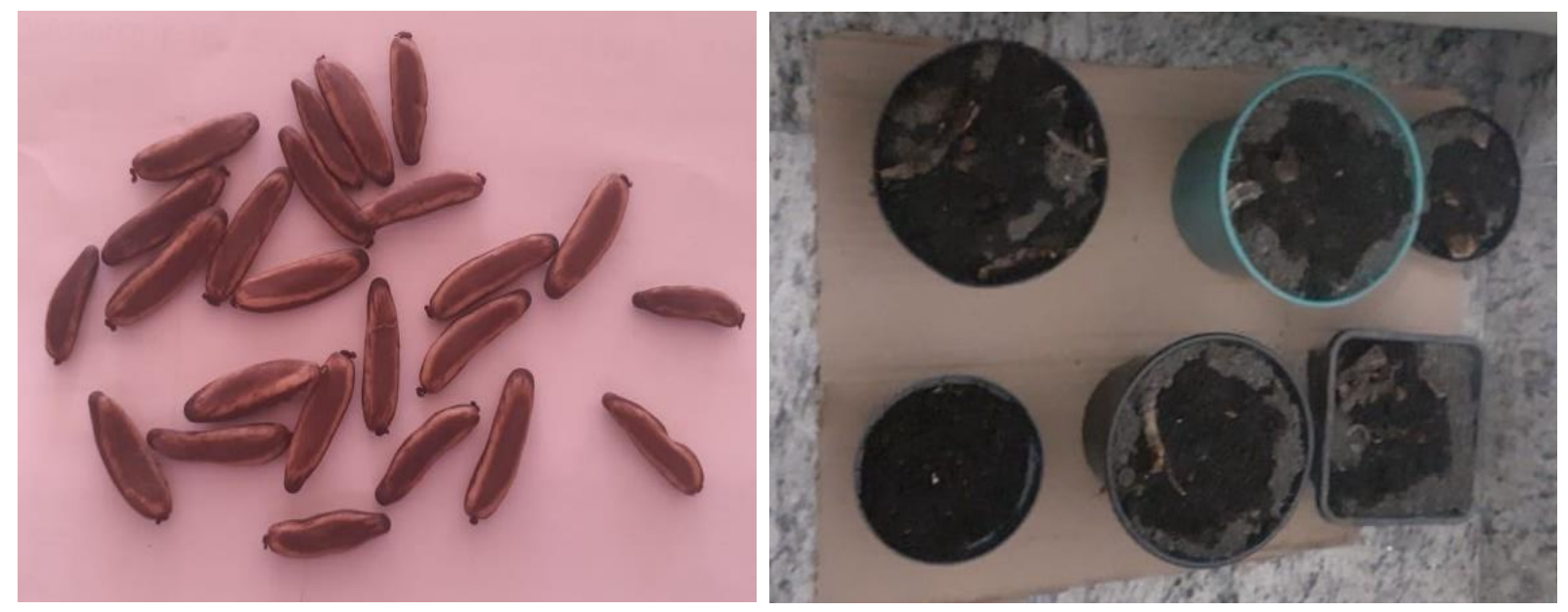

Imagem 1: Esquerda - Sementes de flamboyant colhidas nas ruas de Soure (Ilha do Marajó, Pará). Direita - Sementes de flamboyant plantadas. Foto: FBB.

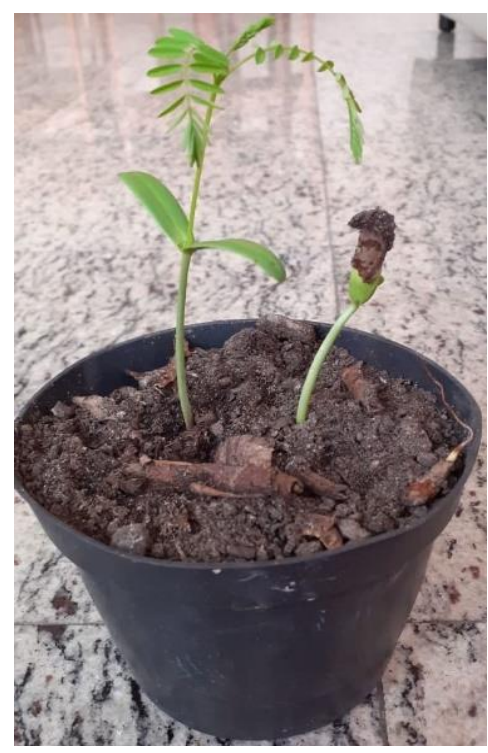

Imagem 2: "Filhas e filhos" de flamboyant se desenvolvendo. Foto: FBB. 


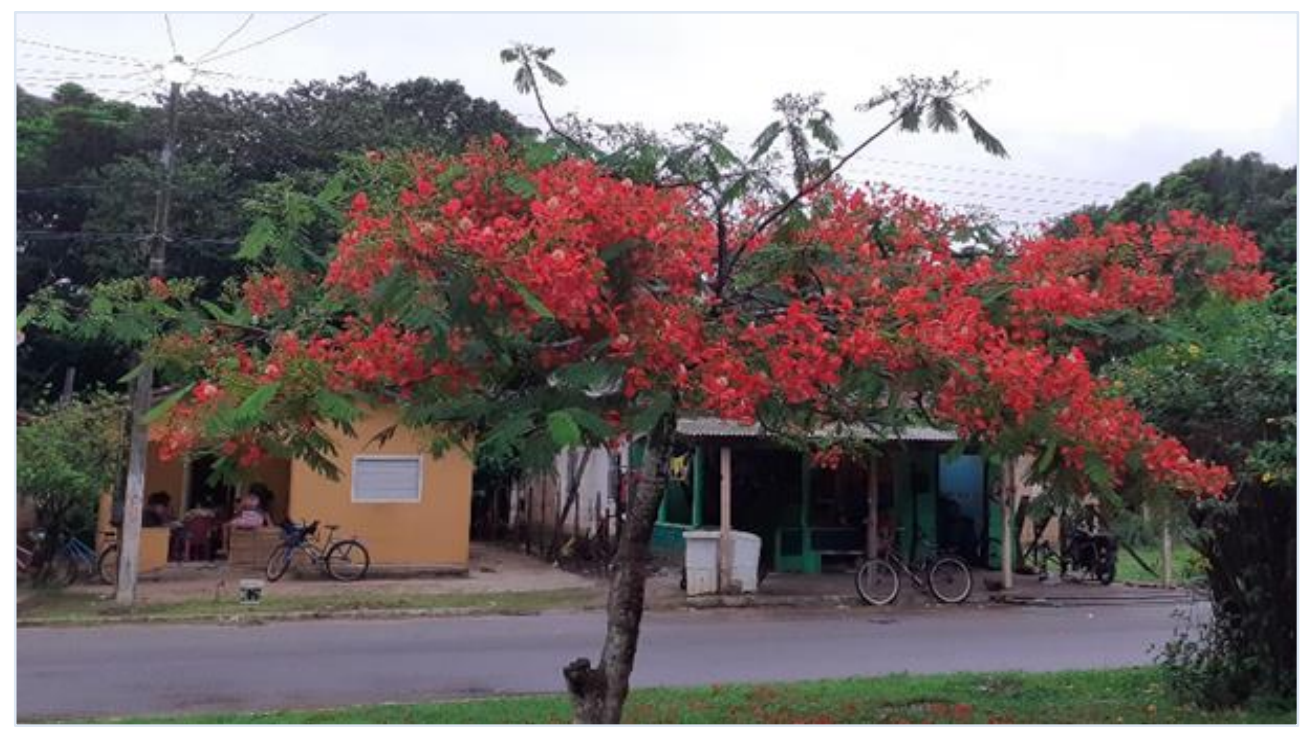

Imagem 3: Flamboyant (Delonix regia Raf.) na Ilha do Marajó (Soure, PA). Foto: FBB.

\section{REFERÊNCIAS}

BOFF, L. A Terra se defende. Revista IHU on-line. Disponível em: http://www.ihu.unisinos.br/78noticias/597421-a-terra-se-defende-artigo-de-leonardo-boff. Acessado em 08 de abril de 2020.

GEERTZ, C. O saber local: novos ensaios em antropologia interpretativa. Tradução de Vera Mello Joscelyne. Petrópolis: Vozes, 1997.

KOPENAWA, D. e ALBERT, B. A queda do céu: palavras de um xamã yanomami. 1. ed. São Paulo: Companhia das Letras, 2015.

OPAS. Organização Pan-Americana de Saúde. Folha informativa - COVID-19 (doença causada pelo novo coronavírus). Disponível em:

https://www.paho.org/bra/index.php?option=com_content\&view=article\&id=6101:covid19\&Itemid=8 75. Acessado em 2 de abril de 2020.

PEREIRA, N. Panorama da alimentação indígena: comidas, bebidas e tóxicos na Amazônia Brasileira. Rio de Janeiro: Editora Livraria São José, 1974. 